International Journal of Clinical Therapeutics and Diagnosis (IJCTD)

ISSN 2332-2926

\title{
Reduction in Dietary Sodium is Associated With a Reduction in Cardiovascular Events and Mortality
}

Aronow WS

Editorial

Cardiology Division, Department of Medicine, New York Medical College/Westchester Medical Center, Valhalla, NY, USA.

\section{*Corresponding Author:}

Wilbert S. Aronow, MD, FACC, FAHA,

Professor of Medicine,Cardiology Division, New York Medical College,

Macy Pavilion, Room 138, Valhalla, NY 10595, USA.

Telephone number: (914) 493-5311

fax number: (914) 235-6274

E-mail: wsaronow@aol.com

Received: August 09, 2014

Published: September 12, 2014

Citation: Aronow WS (2014) Reduction in Dietary Sodium is Associated With a Reduction in Cardiovascular Events and Mortality. Int J Clin Ther Diagn. 2(5e), 1-2. doi: http://dx.doi.org/10.19070/2332-2926$140006 \mathrm{e}$

Copyright: Aronow WS ${ }^{\circ}$ 2014. This is an open-access article distributed under the terms of the Creative Commons Attribution License, which permits unrestricted use, distribution and reproduction in any medium, provided the original author and source are credited.

Most studies have reported a dose-dependent reduction in blood pressure after decreasing sodium intake with the greatest reduction in blood pressure occurring in patients with the highest blood pressures and the most successful interventions [1-3]. A meta-analysis of 56 randomized controlled trials showed a mean blood pressure reduction of $3.7 / 0.9 \mathrm{~mm} \mathrm{Hg}$ for a $100 \mathrm{mmol} /$ day reduction in sodium excretion [4]. Most US adults consume a diet of 5 grams of sodium daily [2]. Guidelines recommend no more than 2,300 $\mathrm{mg}$ of sodium (6 grams of sodium chloride daily) [5] to no more than $1500 \mathrm{mg}$ of sodium daily, especially in black persons, elderly persons, and those with hypertension, diabetes mellitus, and chronic kidney disease [6]. The vast majority of excess dietary sodium is added during processing of foods [7]. In a randomized control trial, 412 persons ate foods with high, intermediate, and low levels of sodium for 30 consecutive days each, in a randomized order [8]. Decreasing the sodium intake from the high to the intermediate level during a control diet lowered the systolic blood pressure by $2.1 \mathrm{~mm} \mathrm{Hg}(\mathrm{p}<0.001)$. Decreasing the sodium intake from the intermediate to the low level during a control diet lowered the systolic blood pressure by an additional $4.6 \mathrm{~mm} \mathrm{Hg}$ [8]. Compared to a ontrol diet with high sodium intake, a DASH diet with low sodium intake reduced the systolic blood pressure by $7.1 \mathrm{~mm} \mathrm{Hg}$ in persons without hypertension and by $11.5 \mathrm{~mm} \mathrm{Hg}$ in persons with hypertension[8].

Excess salt causes severe structural and functional cardiovascular and renal changes experimentally and clinically in patients with hypertension [9]. Dietary sodium restriction reverses vascular endothelial dysfunction in middle aged/older persons with moderately increased systolic blood pressure [10,11].
Numerous clinical studies have demonstrated that reduction of dietary sodium intake is associated with a reduction in cardiovascular events and mortality [12-16]. A one-third reduction in dietary sodium intake in Finland was associated with a reduction in blood pressure and a $75 \%$ to $80 \%$ reduction in both stroke and coronary heart disease mortality [12]. In a veterans retirement home, 1981 men, mean age 74.8 years, were randomized to either a potasium-enriched salt diet or a regular salt diet [13]. At 31-month follow-up, the patients ran domized to the potassiumenriched salt diet had a $41 \%$ reduction (5\% to $63 \%$ ) in cardiovascular disease mortality [13]. Men in the potassium-enriched salt group lived 0.3 to 0.90 years longer and spent 426 US dollars per year less on inpatient care for cardiovascular disease than did men on a regular salt diet [13].

In the Trial of Hypertension Prevention (TOHP), 744 adults aged 30 to 54 years with prehypertension during 1987 to 1990 (TOHP I) and 2382 adults aged 30 to 54 years with prehypertension during 1990 to 1995 (TOHP II) were randomized to dietary sodium reduction or a usual sodium diet $(25 \%$ to $35 \%$ greater sodium intake) [14]. An observational follow-up for cardiovascular events (myocardial infarction, stroke, coronary revascularization, or cardiovascular death) was performed 10 to 15 years after the original trial. This study demonstrated that dietary sodium reduction reduced cardiovascular events by $25 \%(\mathrm{p}=0.04)$ [14].

The Third National Health and Nutrition Examination Survey included 12, 267 US adults [15]. At 14.8-year mean follow-up, higher sodium intake was associated with a $20 \%$ (3\% to $41 \%)$ increase in all-cause mortality per $1000 \mathrm{mg} /$ day of increased sodium intake [15]. For sodium-potassium ratio, the adjusted hazard ratios comparing the highest quartile with the lowest quartile were $46 \%$ (27\% to $67 \%$ ) for all-cause mortality, $46 \%$ (11\% to $92 \%)$ for cardiovascular disease mortality, and $215 \%$ (148\% to $312 \%$ ) for ischemic heart disease mortality [15].

Data from the Health Survey for England included 9183 adults in 2003, 8762 adults in 2006, 8974 adults in 2008, and 4753 adults in 2011 [16]. These data showed that from 2003 to 2011, salt intake measured by 24 hour urinary sodium decreased by 1.9 grams per day $(\mathrm{p}<0.01)$, blood pressure in persons not on antihypertensive medication was lowered by $2.7 / 1.1 \mathrm{~mm} \mathrm{Hg}(\mathrm{p}<0.001)$, mortality from stroke was decreased by $42 \%(\mathrm{p}<0.001)$, and mortality from ischemic heart disease was decreased by $40 \%(p<0.001)$ [16].

On the basis of the available data, reduction of dietary sodium intake by reducing sodium content in processed food and by not adding salt to food would lead to a reduction in blood pressure and to a reduction in cardiovascular events and mortality. A na- 
tional salt reduction program is one of the simplest and most cost-effective ways of improving public health [17].

\section{References}

[1]. US Department of Health and Human Services and US Department of Agriculture. (2010) Dietary Guidelines for Americans. (7th edn). Washington DC: US Government Printing Office, January, 2011.

[2]. Panel on Dietary Reference Intakes for Electrolytes and Water, Standing Committee on the Scientific Evaluation of Dietary reference Intakes, Food and Nutrition Board, Institute of Medicine of the National Academies. (2005) Dietary Reference Intakes for Water, Potassium, Sodium, Chloride, and Sulfate. National Academies Press. Washington DC.

[3]. Whelton PK. (2011) Urinary sodium and cardiovascular disease risk. Informing guidelines for sodium consumption. JAMA 306: 2262-2264.

[4]. Midgley JP, Matthew AG, Greenwood CM. (1996) Effect of reduced dietary sodium on blood pressure: a meta-analysis of randomized controlled trials. JAMA 275: 1590-1597.

[5]. Aronow WS, Fleg JL, Pepine CJ. (2011) ACCF/AHA 2011 expert consensus document on hypertension in the elderly: a report of the American College of Cardiology Foundation Task Force on Clinical Expert Consensus Documents. Developed in collaboration with the American Academy of Neurology, American Geriatrics Society, American Society for Preventive Cardiology, American Society of Hypertension, American Society of Nephrology, Association of Black Cardiologists, and European Society of Hypertension. J Am Coll Cardiol 57: 2037-2114.

[6]. US Department of Health and Human Services and US Department of Agriculture. (2005) Dietary Guidelines for Americans. (6th edn) US Govern- ment Printing Office. Washington DC.

[7]. Mattes RD, Donnelly D. (1991) Relative contributions of dietary sodium sources. J Am Coll Nutr 10: 383-393.

[8]. Sacks FM, Svetkey LP, Vollmer WM. (2001) Effects on blood pressure of reduced dietary sodium and the Dietary Approaches to Stop Hypertension (DASH) diet. N Engl J Med 344: 3-10.

[9]. Frohlich ED, Susic D. (2011) Sodium and its multiorgan targets. Circulation 124: 1882-1885.

[10]. Jablonski KL, Racine ML, Geolfos CJ. (2013) Dietary sodium restriction reverses vascular endothelial dysfunction in middle-aged/older adults with moderately elevated systolic blood presure. J Am Coll Cardiol 61: 335-343.

[11]. Celermajer DS, Neal B. (2013) Excessive sodium intake and cardiovascular disease. A-salting our vessels. J Am Coll Cardiol 61: 344-345.

[12]. Karppanen H, Mervaala E. (2006) Prog Cardiovasc Dis 49: 59-75.

[13]. Chang HY, Hu YW, Yue CS. (2006) Effect of potassium-enriched salt on cardiovascular mortality and medical expenses of elderly men. Am J Clin Nutr 83: 1289-1296.

[14]. Cook NR, Cutler JA, Obarzanek E. (2007) Long term effects of dietary sodium reduction on cardiovascular disease outcomes: observational followup of the trials of hypertension prevention (TOHP). BMJ 334: 885-888.

[15]. Yang Q, Liu T, Kuklina EV. (2011) Sodium and potassium intake and mortality among US adults: prospective data from the Third National Health and Nutrition Examination Survey. Arch Intern Med 171: 1183-1191.

[16]. He FJ, Pombo-Rodrigues S, Macgregor GA. (2014) Salt reduction in England from 2003 to 2011: its relationship to blood pressure, stroke and ischaemic heart disease mortality. BMJ Open 4:45-49.

[17]. Webster JL, Dunford EK, Hawkes C, Neal BC. (2011) Salt reduction initiatives around the world. J Hypertens 29: 1043-1050 